\title{
THE FORMATION AND USE OF THE CONSTRUCTION ENTERPRISE BRAND TO ENSURE INTERACTION WITH STAKEHOLDERS
}

\author{
Mamonov K. ${ }^{1}$, Velychko V. ${ }^{2}$, Grytskov E. ${ }^{3}$, Troian V. \\ ${ }^{1}$ ScD. O. M. Beketov National University of Urban Economy in Kharkiv, Department of Land Administration and \\ Geoinformation Systems, Kharkiv, Ukraine. \\ Tel.+380992917354. E-mail: kostia.mamonov2017@gmail.com \\ ${ }^{2}$ ScD. O. M. Beketov National University of Urban Economy in Kharkiv, Department of Land Administration and \\ Geoinformation Systems, Kharkiv, Ukraine, E-mail: hcsms.07@gmail.com \\ ${ }^{3}$ ScD. O. M. Beketov National University of Urban Economy in Kharkiv, Department of Land Administration and \\ Geoinformation Systems, Kharkiv, Ukraine, E-mail: pikilnyak@gmail.com \\ ${ }^{4}$ ScD. O. M. Beketov National University of Urban Economy in Kharkiv, Department of Enterprise and Business \\ Administration, Kharkiv, Ukraine, E-mail: troyan.vlada@gmail.com
}

Received 2702202002 27, Accepted 07122020

\begin{abstract}
The purpose of the article is to determine the organizational basis for the formation and use of the construction enterprises brand on the scenario approach, which made it possible to build an organizational and economic scheme. The necessity of creating the organizational basis for the formation and use of the construction enterprises brand to ensure interaction with stakeholders is proved. The organizational basis for the formation and use of the brand of construction enterprises, based on the results of an integrated assessment under its components is determined. An important direction in the development of organizational measures of particular importance is the establishment of a causal relationship between the integral indicator of the brand formation and use and the system factor characterizing the capabilities of construction enterprises and the effectiveness of their activities (an integral indicator of investment attractiveness). To establish a causal relationship, the method of economic and mathematical modelling is used. To determine the level of the investment attractiveness systemic factor, its forecasting using model and coefficient of determination, based on the established causal relationship between the integral indicator of the brand formation and use and the systemic factor of investment attractiveness was performed. The results of establishing a causal relationship between the integral indicator of brand formation and use and the systemic factor of investment attractiveness are presented. The organizational measures for the formation and use of the brand of construction enterprises are proposed. The crisis, stagnation and development scenarios depending on the values of the integral indicator of the formation and use of the construction enterprise brand and the systemic factor of investment attractiveness were proposed.
\end{abstract}

Keywords: brand, construction enterprise, economic modeling, mathematical modeling, stakeholders.

JEL Codes: C02; C51; L1.

\section{Introduction}

In modern conditions, which are characterized by permanent transformations, deepening crisis, the movement towards European economic institutions, the growing reputation of domestic enterprises, increasing the effectiveness of brand policy and interaction with stakeholders, increasing the level of their social corporate responsibility are gaining importance. In this process, construction enterprises occupy a central place, since they influence the development of other areas of the state economy and ensure the effectiveness of its functioning. The directions of brand formation and use are defined in the works of (Brooking, 2001; Butnik-Seversky, 2002; Edwinsson and Malone, 1999; Keller, 1993, 1998, 2002; Knapp, 2000; LePle et al., 2004; Mamonov, 2012; Stuart, 2007) and others. The problems of ensuring interaction with stakeholders were studied by (Ackoff, 1982; Ammari, 2012; D’anselmi, 2011; Cleland, 2004; Freeman, 1984) and others.

Copyright (C) 2020. Published by Vytautas Magnus University. This is an open access article distributed under the terms of the Creative Commons Attribution Non-Commercial 4.0 (CC BY-NC 4.0) license, which permits unrestricted use, distribution, and reproduction in any medium provided the original author and source are credited. The material cannot be used for commercial purposes. 
Studies on the formation and use of corporate social responsibility are presented in the works of (Blagov, 2011; Wittenberg, 2011; Matveenko, 2011; Zaretsky and Ivanova, 2016; Saprykina et al., 2011) et al.

The purpose of the article is to determine the organizational basis for the formation and use of the construction enterprises brand based on the scenario approach, which made it possible to build an organizational and economic scheme. For solving this problem, it is necessary to:

- determine the organizational and economic components of the formation and use of the brand;

- determine the factors, wich are forming corporate social responsibility with ensuring interaction with stakeholders for the development of the brand policy of construction enterprises.

\section{Materials and methods}

The organizational basis for the formation and use of the brand of construction enterprises is based on the results of an integrated assessment in accordance with its components. In particular, in order to ensure the effective formation and use of the brand, JSC "Kyivmiskbud" focuses on organizational measures and changing negative trajectories in the field of emotional attitude to the brand, forming its consumer value, strengthening the power of construction products brand, building corporate culture, corporate security and financial condition. At the same time, in order to ensure the effectiveness of the formation and use of the construction enterprise brand considering the results of an integrated assessment, a further increase in efficiency and the strengthening of stakeholder relations and an increase in the cost of construction products are proposed.

At PJSC "Trust Zhitlobud-1", the organizational measures that consist of changing negative trajectories regarding the emotional attitude of consumers to the brand, its consumer value, ensuring stakeholder relations, strengthening brand power, the level of formation of corporate culture and corporate security were proposed. The need for further growth in brand value and the level of the financial condition of the studied construction enterprise is determined. At all construction enterprises, it was proposed to transform the organizational structure by creating a brand policy implementation department within the existing personnel potential or by reducing other units.

The resulting indicator of the construction enterprises functioning is an indicator of investment attractiveness. Based on the developed models and proposed models, the integral factor of investment attractiveness of construction enterprises was determined in (ISO 26000:2010; Prunenko, 2018):

- Brovarsky factory of building structures - 0.437 ;

- JSC "KDBK" - 0.46;

- JSC "Kyivmiskbud" - 0.44;

- PJSC "Trust Zhitlobud-1" - 0.53;

- JSC "Zhitlobud-2" - 0.43 .

A scale of investment attractiveness values and their characteristics in the studied construction enterprises are proposed. The study found a moderate level of investment attractiveness at Brovarsky Plant of Building Structures, JSC "KDBK", JSC "Kyivmiskbud”, JSC “Zhitlobud-2". The presented directions are not implemented comprehensively and do not have a systemic nature. At PJSC "Trust Zhitlobud-1", the level of investment attractiveness is characterized as significant. An important direction in the development of organizational measures of particular importance is the establishment of a causal relationship between the integral indicator of the brand formation and use and the system factor characterizing the capabilities of construction enterprises and the effectiveness of their activities (an integral indicator of investment attractiveness). To establish a causal relationship, the method of economic and mathematical modeling is used. The results of establishing a causal relationship between the integral indicator of brand formation and use and the systemic factor of investment attractiveness are presented in Fig. 1. 


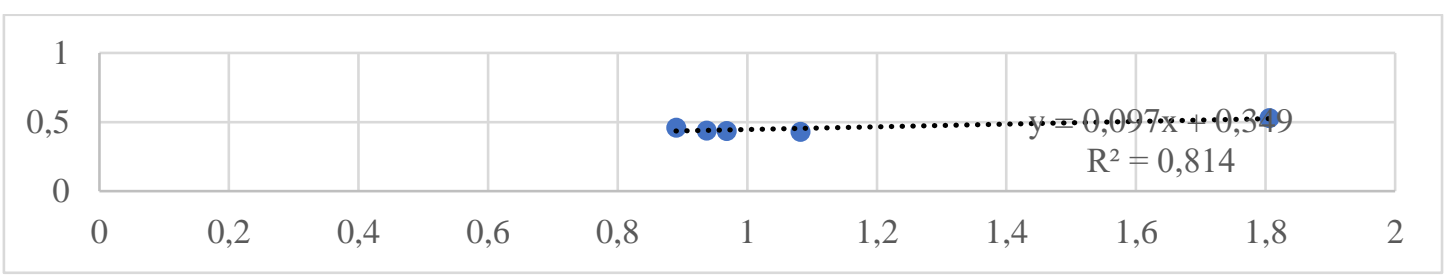

Figure 1. Model and coefficient of determination, determined on the basis of the established causal relationship between the integral indicator of the brand formation and use and the systemic factor of investment attractiveness

To check the adequacy of the model, the adequacy criteria are used: the correlation and determination coefficient, Student's, Fisher's criteria, tests for homo or heteroskedasticity, test for multicollinearity, Darbin-Watson criterio. Certain criteria indicate the adequacy of the developed model and the significant impact of the integral indicator of the construction enterprise brand formation and use on the systemic factor of their investment attractiveness. It should be noted that the indicator of brand formation and use has a significant influence on the systemic factor, which determines its change by $81.4 \%$. To determine the level of the investment attractiveness systemic factor, we will carry out its forecasting using the model presented in Fig. 1. The calculation results are presented in Table 1.

Table 1. Predicting the level of the systemic factor of investment attractiveness depending on the increase of the integral indicator of the formation and use of the construction enterprises

brand, rel. units

\begin{tabular}{|c|c|c|c|c|c|c|c|}
\hline $\begin{array}{l}\text { Increase of the integral indicator of } \\
\text { brand formation and use by }\end{array}$ & $1 \%$ & $2 \%$ & $3 \%$ & $5 \%$ & $10 \%$ & $20 \%$ & $30 \%$ \\
\hline \multirow{5}{*}{$\begin{array}{l}\text { The value of the systemic factor of } \\
\text { investment attractiveness of construction } \\
\text { enterprises }\end{array}$} & 0.444 & 0.445 & 0.446 & 0.448 & 0.453 & 0.462 & 0.472 \\
\hline & 0.436 & 0.437 & 0.438 & 0.440 & 0.445 & 0.455 & 0.464 \\
\hline & 0.441 & 0.442 & 0.443 & 0.445 & 0.45 & 0.459 & 0.469 \\
\hline & 0.525 & 0.526 & 0.527 & 0.529 & 0.534 & 0.544 & 0.553 \\
\hline & 0.455 & 0.456 & 0.457 & 0.459 & 0.464 & 0.473 & 0.483 \\
\hline
\end{tabular}

The changes in the systemic factor of investment attractiveness depending on the increase of the integral indicator of the formation and use of the construction enterprises brand are presented in Table. 2 .

Table 2. Changes in the systemic factor of investment attractiveness depending on the increase of the integral indicator of the formation and use of the construction enterprises brand, rel. units

\begin{tabular}{|c|c|c|c|c|c|c|c|}
\hline $\begin{array}{c}\text { Increase of the integral indicator of } \\
\text { brand formation and use by }\end{array}$ & $\mathbf{1 \%}$ & $\mathbf{2 \%}$ & $\mathbf{3 \%}$ & $\mathbf{5 \%}$ & $\mathbf{1 0 \%}$ & $\mathbf{2 0 \%}$ & $\mathbf{3 0 \%}$ \\
\hline \multirow{3}{*}{$\begin{array}{c}\text { Changes in the systemic factor of } \\
\text { investment attractiveness of } \\
\text { construction enterprises }\end{array}$} & 0.007 & 0.008 & 0.0088 & 0.011 & 0.016 & 0.025 & 0.035 \\
\cline { 2 - 8 } & -0.024 & -0.023 & -0.0218 & -0.020 & -0.015 & -0.005 & 0.004 \\
\cline { 2 - 9 } & 0.001 & 0.002 & 0.0028 & 0.005 & 0.010 & 0.019 & 0.029 \\
\cline { 2 - 8 } & -0.005 & -0.004 & -0.0029 & 0.001 & 0.004 & 0.014 & 0.023 \\
\cline { 2 - 8 } & 0.025 & 0.026 & 0.0269 & 0.029 & 0.034 & 0.043 & 0.053 \\
\hline
\end{tabular}

\section{Results}

As a result of the study of changes in the investment attractiveness systemic factor depending on the increase of the integral indicator of brand formation and use, it was found that only an increase 
in the integral indicator by $30 \%$ leads to positive changes and an increase in the system factor at all construction enterprises. Therefore, one of the directions for the implementation of organizational measures is to ensure the increase of the integral indicator to the given level by enhancing the formation and use of the brand. For the development and implementation of organizational measures, it is proposed to use a scenario approach, which characterizes the state and features of the formation and use of the construction enterprise brand and their impact on investment attractiveness.

Thus, as a result of the study, a scenario approach was implemented in order to develop the organizational foundations. The scenarios depending on the values of the integral indicator of the formation and use of the construction enterprise brand and the systemic factor of investment attractiveness were proposed: the crisis, stagnation, development scenario.

Summarizing the foregoing, an organizational and economic scheme for the formation and use of a construction enterprise brand has been developed (Fig. 2). The organizational and economic scheme consists of three components:

1) Information and analytical component, which is formed from the directions of determining the factors affecting the creation and use of the construction enterprises brand, the corresponding information and analytical support, which consists of statistical, economic, financial and other data affecting the formation and use of the brand, the construction of quasimetric models of the transition from selected factors to relevant indicators to build a two-level system. The information and analytical component allow creating a basis for assessing the level of formation and use of the construction enterprises brand.

2) The economic component is based on the integrated approach proposed by the author to the integrated assessment of the formation and use of the construction enterprise brand. As a result of its implementation, the corresponding integral indicator is determined, the value of which $(\mathrm{B} \geq 3)$ allows either to build a quantitative platform for the formation and use of the brand (if the condition is "Yes"), or to abandon this process (the condition is not fulfilled - "No") and start process of forming factors.

3) The determination of the organizational component is carried out on the constructed quantitative platform and includes:

- modelling the impact of the integral indicator of brand formation and use on the systemic factor of investment attractiveness;

- developing scenarios for changing the integral indicator of the formation and use of the brand and the systemic factor of investment attractiveness.

According to the developed scale of indicators for the formation and use of the brand and the systemic factor of investment attractiveness, the boundary values of the increase of indicators are determined. 


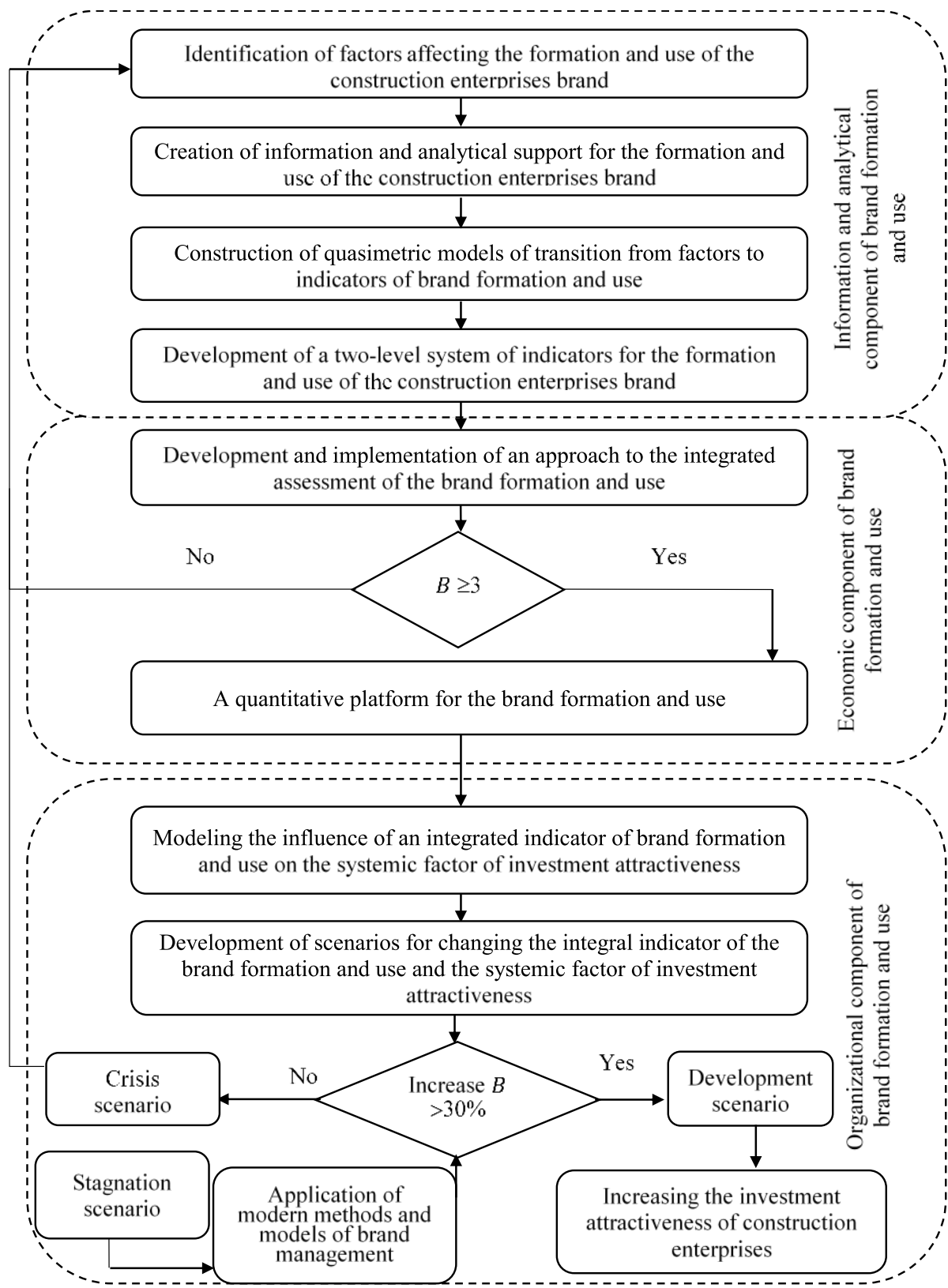

Figure 2. The organizational and economic scheme of the formation and use of the construction enterprises brand

It has been established that if the integral indicator of the formation and use of the construction enterprises brand exceeds $30 \%$, it ensures the growth of the systemic factor of investment attractiveness at all construction enterprises. Therefore, a development scenario, which ensures the increase of investment attractiveness is determined. Otherwise $(\mathrm{B} \leq 30 \%)$, depending on the state and characteristics of the transformation processes, which are taking place at the construction enterprise and in the sphere of formation and use of the construction enterprise brand, either a crisis or stagnation scenario is determined. If the latter scenario is determined, then by applying modern methods and models, the condition ( $\mathrm{B} \geq 30 \%$ ) is checked again for compliance. In the case of its implementation, a proceed to the development scenario is carried out. If the condition is not met, then proceed to the crisis scenario, which provides for the determination of factors affecting the formation and use of the construction enterprises brand (at the beginning of the process of building the organizational and economic scheme for the formation and use of the construction enterprises brand). 
In the corporate governance system, corporate social responsibility is of particular importance, which is characterized as a system, which is formed by an enterprise to ensure the increase of welfare of the population and environmental protection [28]. As a result of the study, the factors, which influence the formation and implementation of corporate governance in order to ensure interaction with stakeholders and the development of brand policy were proposed:

4) The directions and features of corporate governance at construction enterprises $\left(S_{31}\right)$.

5) The formation and use of corporate governance tools to ensure interaction with stakeholders $\left(S_{32}\right)$.

6) The formation, disclosure, use and protection of information in the corporate governance system $\left(S_{33}\right)$.

7) The directions of corporate interaction between stakeholders to ensure the development of enterprises $\left(S_{34}\right)$. $\left(S_{35}\right)$.

8) The formation and use of corporate culture to ensure interaction between stakeholders

9) The formation and implementation of social corporate responsibility in the corporate governance system of construction enterprises $\left(S_{36}\right)$.

10) The completeness and level of application of regulatory support for corporate governance $\left(S_{37}\right)$

11) The level of institutional support for the corporate governance of construction enterprises $\left(S_{38}\right)$.

The factors, which are forming corporate social responsibility with ensuring interaction with stakeholders for the development of the brand policy of construction enterprises are identified: the formation and implementation of organizational management in the corporate social responsibility system; ensuring human rights; the characteristics of labor practices; ensuring the protection of the environment; good practices in the corporate responsibility system; solving problems related to consumers; ensuring increased enterprise trust in corporate social responsibility and others.

\section{Conclusions}

Therefore, the organizational basis for the formation and use of the construction enterprises brand on the scenario approach is determined, which made it possible to build an organizational and economic scheme. Thus, as a result of the study, the organizational and economic components of the formation and use of the brand were determined, which made it possible to manage this process and create conditions for the growth of the investment attractiveness of construction enterprises. The proposed factors, which are forming corporate social responsibility with ensuring interaction with stakeholders for the development of the brand policy of construction enterprises, are proposed. This provides a quantitative basis for making justified management decisions and ensuring their monitoring.

Thus, as a result of the study, a scenario approach was implemented to develop the organizational foundations. The crisis, stagnation and development scenarios depending on the values of the integral indicator of the formation and use of the construction enterprise brand and the systemic factor of investment attractiveness were proposed, which allow developing an organizational and economic scheme for the formation and use of a construction enterprise brand.

\section{References}

Ackoff, R. (1982). The Art of Problem Solving, ed. E. G. Kovalenko. - Moscow: Mir, 482 p.

Ammari, A.O. (2012). Classification of stakeholders based on mutual views // Act. Probl. Econ.: Sci. Econ. J. No.8: 150-155.

Blagov, Yu. (2011). Corporate social responsibility: evolution of the concept. - St. Petersburg: Graduate School of Management, , $272 \mathrm{p}$.

Brooking, E. (2001). Intellectual capital: the key to success in the new millennium. - Saint-Peterburg: Peter, 288 p. 
Butnik-Seversky, O.B. (2002). Intellectual capital: a theoretical aspect // Intellectual capital, Vol. 1: 16-27.

Cleland, D. (1986). Project stakeholder management // Project Management Journal. Vol. 17, No. 4: 36-44.

D'Anselmi, P. (2011). Values and stakeholders in an era of social responsibility. - New York: Free Press, 27 p.

Edwinsson, L. Malone, M. (1999). Intellectual capital. Determining the true value of the company / New postindustrial wave in the West: Anthology, ed. V. L. Inozemtseva. - Moscow: Academia, 447 p.

Freeman, E. (1984). Strategic Management: A Stakeholder approach. - Boston: Pitman, 34 p.

Publication

International standard ISO 26000:2010, 2010. Guidance on social responsibility (IDT). ISO 26000 Post

26000_and_OECD_Guidelines_MNE_PPO_v1.pdf http://iso26000.info/wpcontent/uploads/2017/02/ISO-

Keller, K.L. (1993). Conceptualizing, measuring and managing customer-based brand equity // Journal of Marketing. Vol. 57. No. 1: 1-22.

Keller, K.L. (1998). Strategic brand management: building, measuring, and managing brand equity. - Upper Saddle River: Prentice Hall, 86 p.

Keller, K.L. (2002). Branding and Brand Equity. Marketing Science Institute. - Massachusetts: Cambridge, 86 p. Knapp, D.E. (2000). The Brand Mindset. - New York: The McGraw-Hill, 304 p.

Leple, J.F., Davis, S.V., Parker, L.M., Stambo, S., Samuelson, L., Nobis, E., Sturgill, K. (2004). Brand development strategies. An original hands-on tool for your brand leadership. - Moscow: Balance Club.

Mamonov, K.A. (2012). Stakeholder Strategy of Value-Oriented Brand Capital Management of Construction Companies. Thesis (ScD). - Kharkov: KNAGH, 503 p.

Matveenko, A. (2011). Corporate social responsibility as a factor of enterprise sustainability. - Moscow: AP Science and Education, 205 p.

Prunenko, D.A. (2018). Theoretical and methodological aspects of the formation and implementation of the strategy for managing the intellectual capital of construction enterprises. Thesis (ScD). - Kharkov: KNUMG, KNUBA, $604 \mathrm{p}$.

Saprykina, M., Lyashenko, A., Saensus, M., Gorodskoy, G. (2011). Corporate social responsibility: models and managerial practice: Textbook. - Moscow: LLC Farbovanyy lyst, 480 p.

Stuart, T. A. (2007). Intellectual capital. A new source of wealth of organizations, ed V. Nozdrina. - Moscow: Pokolenie, 368 p.

Wittenberg, E. (2011). Social responsibility of business in the post-Soviet space. - Moscow: Publishing Center of RSUH, 72 p.

Zaretsky, A., Ivanova, T. (2016). Corporate social responsibility: world and domestic practice: Textbook. Minsk: KNORUS, 292 p. 